\title{
cAMP Response Element-Binding Protein Is Essential for the Upregulation of Brain-Derived Neurotrophic Factor Transcription, But Not the Behavioral or Endocrine Responses to Antidepressant Drugs
}

\author{
Alana C. Conti, ${ }^{1}$ John F. Cryan, ${ }^{2}$ Ashutosh Dalvi, ${ }^{2}$ Irwin Lucki, ${ }^{1,2,3}$ and Julie A. Blendy ${ }^{1,3}$ \\ Departments of ${ }^{1}$ Pharmacology and ${ }^{2}$ Psychiatry, and ${ }^{3}$ Center for Neurobiology and Behavior, University of Pennsy/vania, \\ Philadelphia, Pennsylvania 19104-6084
}

Antidepressant drugs activate the cAMP signal transduction pathway through a variety of monoamine neurotransmitter receptors. Recently, molecular studies have identified a role for cAMP response element-binding protein (CREB) in the mechanism of action of chronically administered antidepressant drugs. However, the function of CREB in the behavioral and endocrine responses to these drugs has not been thoroughly investigated. We have used CREB-deficient mice to study the effects of two antidepressants, desipramine (DMI) and fluoxetine (FLX), in behavioral, endocrine, and molecular analyses. Behaviorally, CREB-deficient mice and wild-type mice respond similarly to DMI and FLX administration in the forced swim test and tail suspension test. Furthermore, the ability of DMI to suppress an acute corticosterone response after swim stress is

The therapeutic efficacy of antidepressant drugs has been realized for years, however, current knowledge regarding their mechanisms of action remains incomplete. In clinically depressed patients, behavioral symptoms of depression are alleviated after a few weeks of antidepressant administration, whereas chronic, long-term use of these drugs over months, is required to prevent recurrent depressive episodes (Goodwin and Jamison, 1990). Hence, short-term neuroadaptations caused by antidepressants may eliminate clinical features of depression, whereas long-term cellular alterations may be critical to maintain efficacy observed with continued antidepressant use. Experimental models that evaluate various components of antidepressant action such as the behavioral, biochemical, and molecular effects, have facilitated our understanding of the complexities associated with clinical depression and its treatments.

Animal models that assess antidepressant efficacy as a reduction in behavioral immobility, such as the forced swimming test (FST) and the tail suspension test (TST), are sensitive to alterations in neurotransmitter concentration caused by single or subchronic administration of the major classes of antidepressants

\footnotetext{
Received Oct. 24, 2001; revised Jan. 24, 2002; accepted Feb. 1, 2002.

This work was supported by a National Alliance for Research on Schizophrenia and Depression Young Investigator grant and National Institute on Drug Abuse Grant DA-1169-01A2 (J.A.B.) and National Institutes of Health Grant MH 48125 (I.L.). We thank Sheila Upton and Misty Godfrey for their technical expertise.

Correspondence should be addressed to Julie A. Blendy, Department of Pharmacology, 125 John Morgan, 3620 Hamilton Walk, Philadelphia, PA 19104-6084. E-mail: blendy@pharm.med.upenn.edu.

J. F. Cryan's present address: Nervous Systems Research, Novartis Pharma AG, Basel, CH-4002 Switzerland.

A. Dalvi's present address: Department of Psychopharmacology, H. Lundbek, Ottilavej 9, DK-2500, Valby, Denmark.

Copyright (C) 2002 Society for Neuroscience $\quad 0270-6474 / 02 / 223262-07 \$ 15.00 / 0$
}

maintained in CREB-deficient mice. However, upregulation of a molecular target of CREB, BDNF, is abolished in the CREBdeficient mice after chronic administration of DMI. These data are the first to demonstrate that CREB activation is upstream of BDNF mechanistically in response to antidepressant drug treatment. Therefore, although behavioral and endocrine responses to antidepressants may occur by CREB-independent mechanisms, CREB is critical to target gene regulation after chronic drug administration, which may contribute to long-term adaptations of the system to antidepressant drug treatment.

Key words: CREB; BDNF; antidepressant; gene expression; forced swimming test; tail suspension test; desipramine; fluoxetine
(Page et al., 1999; Lucki et al., 2001). Similarly, acute antidepressant treatment attenuates swim stress-induced corticosterone release (Baez and Volosin, 1994; Connor et al., 1997). In contrast, alterations in gene transcription are primarily associated with chronic administration of antidepressant drugs.

Recently, the cAMP signaling pathway has been implicated in antidepressant action after chronic treatment. Increases in cAMP, via receptor adenylate cyclase activity, increase phosphorylation of the cAMP response element-binding protein (CREB). By binding to cAMP response element (CRE) sites, CREB mediates transcriptional responses to elevated levels of cAMP. CRE-mediated gene transcription is upregulated after chronic antidepressant treatment in the rat cortex and hippocampus (Thome et al., 2000). CREB expression and function are upregulated by chronic antidepressant treatment in both rodents and humans (Nibuya et al., 1996; Dowlatshahi et al., 1998). CREB upregulation may activate downstream targets such as brainderived growth factor (BDNF) after antidepressant treatment by binding to $\mathrm{CRE}$ elements located in the promoter region of the BDNF gene (Nibuya et al., 1995; Shieh et al., 1998; Tao et al., 1998). Temporal and regional upregulation of BDNF mRNA and its receptor, trkB, parallels CREB mRNA activation after chronic antidepressant administration (Nibuya et al., 1995, 1996).

By using a CREB-deficient mouse model $\left(\mathrm{CREB}^{\alpha \Delta}\right.$ mutant mice) (Hummler et al., 1994; Blendy et al., 1996), we are able to examine the direct role of CREB in a variety of antidepressant drug effects, such as behavioral and endocrine responses, that are manifested after acute, subchronic, or chronic drug administration, and molecular responses, that occur only after chronic treatment. We have evaluated behavioral responses to acute and chronic antidepressant treatment in the FST and the TST. In 
addition, we have examined FST-induced hypothalamic-pituitary-adrenal (HPA) axis activation and the ability of desipramine to blunt corticosterone release. Finally, we quantified BDNF mRNA transcription in the frontal cortex and hippocampus after subchronic and chronic antidepressant administration. These brain regions were chosen because evidence suggests they are key neuroanatomical substrates for antidepressant action (Heninger and Charney, 1987; Jacobson and Sapolsky, 1991; Duman et al., 1997). Our results demonstrate that antidepressantinduced behaviors are still present in $\mathrm{CREB}^{\alpha \Delta}$ mutant mice, despite a dramatic reduction in CREB activity. Furthermore, swim stress-induced elevation in corticosterone is maintained in CREB-deficient mice, as is the effectiveness of desipramine to block this response. However, increases in BDNF are abolished in $\mathrm{CREB}^{\alpha \Delta}$ mutant mice after chronic treatment, identifying $\mathrm{CREB}$ as an upstream activator of BDNF. These data clearly establish that CREB is essential for developed long-term transcriptional changes associated with chronic antidepressant treatment and suggest that the behavioral and endocrine effects of antidepressants can occur in the face of dramatic reductions in CREB activity.

\section{MATERIALS AND METHODS}

Animals. The $\mathrm{CREB}^{\alpha \Delta}$ mutation has been backcrossed multiple times to the inbred mouse strains $129 \mathrm{SvEv}$ and $\mathrm{C} 57 \mathrm{Bl} / 6$ (N9 and N11, respectively). For all experiments described here, $\mathrm{CREB}^{\alpha \Delta}$ mutants and wild-type controls are F1 hybrids obtained from crossing mice heterozygous for the CREB mutation from each strain. Thus in the F1 generation, each individual mouse is heterozygous for all loci that differ between the parental strains and are genetically identical with the exception of the CREB locus. This breeding scheme allows us to rigorously control for genetic background of experimental animals over time and is in agreement with the recommendations of the Branbury Conference on Genetic Background in Mice (Silva et al., 1997). All mice (3-5 months old, 23-40 gm) were group-housed and maintained on a $12 \mathrm{hr}$ light/dark cycle with food and water available ad libitum in accordance with the University of Pennsylvania Animal Care and Use Committee. All experimental testing sessions were conducted between 12:00 and 6:00 P.M., with animals randomly assigned to treatment conditions and tested in counterbalanced order.

Drugs. Desipramine (DMI) (Sigma, St. Louis, MO) and fluoxetine (FLX) (Lilly Pharmaceuticals, Indianapolis, IN) were freshly prepared before use and injected intraperitoneally or subcutaneously using a volume of $10 \mathrm{ml} / \mathrm{kg}$. All drug doses were calculated as milligrams per kilogram base weight and were dissolved in $0.9 \%$ saline.

Forced swimming test. To facilitate adaptation to novel surroundings, mice were transported to the testing room at least $1 \mathrm{hr}$ before testing. All experimental testing sessions were conducted between 12:00 and 6:00 P.M., with animals randomly assigned to treatment conditions and tested in counterbalanced order. Briefly, swim sessions were conducted by placing mice in individual glass cylinders $(46-\mathrm{cm}-$ tall $\times 20.5-\mathrm{cm}-$ diameter) containing $23-25^{\circ} \mathrm{C}$ water, 10 -cm-deep. Although the procedure was essentially similar to that described by Porsolt et al. (1977) for rats, a cylinder of larger diameter was used because a larger tank diameter increases predictive validity in the mouse FST (Sunal et al., 1994). Subjects were given a $15 \mathrm{~min}$ preswim, occurring $23.5 \mathrm{hr}$ before the first test swim. On test days a 6 min test duration was used, and the water was changed between subjects. All test sessions were recorded by a video camera positioned directly above the cylinders. Videotapes were scored blind by a trained observer. The behavioral measure scored was the duration of "immobility," defined as the time when mice were judged to be making escape-motivated movements necessary to keep their head above water.

Saline or DMI was administered subchronically by giving three injections over a $24 \mathrm{hr}$ period ( $n=8$ per group). Doses were spaced 23.5, 5.0, and $1.0 \mathrm{hr}(10 \mathrm{mg} / \mathrm{kg}$, i.p.; $10 \mathrm{mg} / \mathrm{kg}$, i.p.; and $20 \mathrm{mg} / \mathrm{kg}$, s.c.; respectively) before the first test swim. Data obtained from pilot experiments showed robust behavioral changes after this dosing strategy. For chronic experiments animals were injected twice daily with saline or DMI $(10 \mathrm{mg} / \mathrm{kg}$, i.p.; $n=9$ per group). On test days, morning injections were administered
$5 \mathrm{hr}$ before FST, and afternoon injections (saline or $20 \mathrm{mg} / \mathrm{kg}$ DMI, s.c.) were administered $1 \mathrm{hr}$ before FST. This dosing regime was used to allow for comparison between the acute FST studies and the repeated FST during the chronic study.

Tail suspension test. Mice were tested in a modified version of the tail suspension test (Steru et al., 1985). Animals were adapted to novel surroundings and tested as described for the FST. Subjects were each given saline, DMI, or FLX (20 mg/kg, i.p.; $n=8-10$ per group). Thirty minutes after injection mice were individually suspended by the tail to a horizontal ring-stand bar (distance from floor, $35 \mathrm{~cm}$ ) using Fisher Scientific (Pittsburgh, PA) adhesive tape affixed $2 \mathrm{~cm}$ from the tip of the tail. Dosing paradigm was selected from previous studies showing robust behavioral changes under these conditions (Lucki et al., 2001; Mayorga and Lucki, 2001). Mice demonstrated several escape-oriented behaviors interspersed with bouts of immobility as the session progressed. A 6 min test session was used that was recorded by a video camera positioned in front of the TST apparatus. Videotapes were scored by a trained observer who was blind to the experimental conditions. The behavioral measure scored was the duration of "immobility," defined as the time when mice were judged to cease escape-motivated behaviors.

RNA isolation and RNase protection assays. Animals were killed at 24 $\mathrm{hr}$ after testing for chronic (21 d) or $20 \mathrm{~min}$ after testing for subchronic (24 hr) antidepressant or saline treatment. After cervical dislocation, brains were dissected for RNA analysis ( $n=8-10$ per group). Frontal cortex and hippocampal RNA was isolated using guanidine isothiocyanate (Chomczynski and Sacchi, 1987). The quality of the RNA samples was determined by ethidium bromide staining of $18 \mathrm{~S}$ and $28 \mathrm{~S}$ ribosomal RNAs after fractionation on denaturing agarose gels.

Ribonuclease protection analysis was performed as described previously (Kaestner et al., 1989). The BDNF probe used for RNase protection was cloned by reverse transcriptase-PCR using mouse brain cDNA with primers from positions 430 to 739 of the mouse BDNF cDNA. The PCR product was subcloned into pBluescript KS to yield plasmid pmBDNF/EcoRV. Briefly, $\alpha-{ }^{32} \mathrm{P}$ UTP-labeled antisense probe for BDNF (320 bp) was hybridized overnight at $56^{\circ}$ against $20 \mu \mathrm{g}$ frontal cortex or hippocampal RNA in $80 \%$ formamide. A $150 \mathrm{bp}$ subclone of the mouse TATA binding protein (TBP) gene (Tamura et al., 1991) was used as an internal control, because the mRNA of this gene is expressed in most tissues in approximately equal amounts. After hybridization, excess probes were digested with RNases A and T1. Protected probe-mRNA hybrids were analyzed on denaturing $6 \%$ polyacrylamide gels. Signals were quantified using a PhosphorImager (Molecular Dynamics, Sunnyvale, CA) and normalized over those of TBP.

Plasma corticosterone assays. Trunk blood was collected from each animal at the time of killing ( 20 min after acute FST test session; $n=8$ per group), separated into plasma by centrifugation, and stored at $-20^{\circ} \mathrm{C}$ until assayed. Plasma corticosterone was measured by radioimmunoassay using a commercially available kit (ICN Biomedicals Inc., Cleveland, $\mathrm{OH}$ ). Intra-assay coefficient of variation was $<20 \%$ (average coefficient of variation of $6.22 \%$ ).

Statistical analysis. All data were analyzed by a two-factor ANOVA, with Fisher's or Newman-Keuls tests used for post hoc comparisons of individual means. Repeated FST data were analyzed with a repeated measures ANOVA, with Newman-Keuls test used for post hoc comparisons of individual means. Comparisons were considered statistically significant when $p$ values were $<0.05$.

\section{RESULTS}

\section{Subchronic desipramine administration reduces immobility in the FST}

To test the role of CREB in DMI-mediated behavioral alterations in the FST we administered saline and DMI (three doses over 24 $\mathrm{hr}, 10 \mathrm{mg} / \mathrm{kg}$, i.p.; $10 \mathrm{mg} / \mathrm{kg}$, i.p.; and $20 \mathrm{mg} / \mathrm{kg}$, s.c.) to wild-type and $\mathrm{CREB}^{\alpha \Delta}$ mutant mice and measured immobility. Salinetreated $\mathrm{CREB}^{\alpha \Delta}$ mice exhibited significantly reduced baseline immobility in the FST compared with wild-type saline controls (Fig. 1). Immobility times of saline-treated CREB mutant mice were similar to those of wild-type mice receiving DMI. This reduction in immobility is not a result of a general alteration in locomotor activation in these mutant mice. There is no quantifiable difference in basal locomotion when tested in home cage activity monitors (Walters and Blendy, 2001) or in swim speed or 


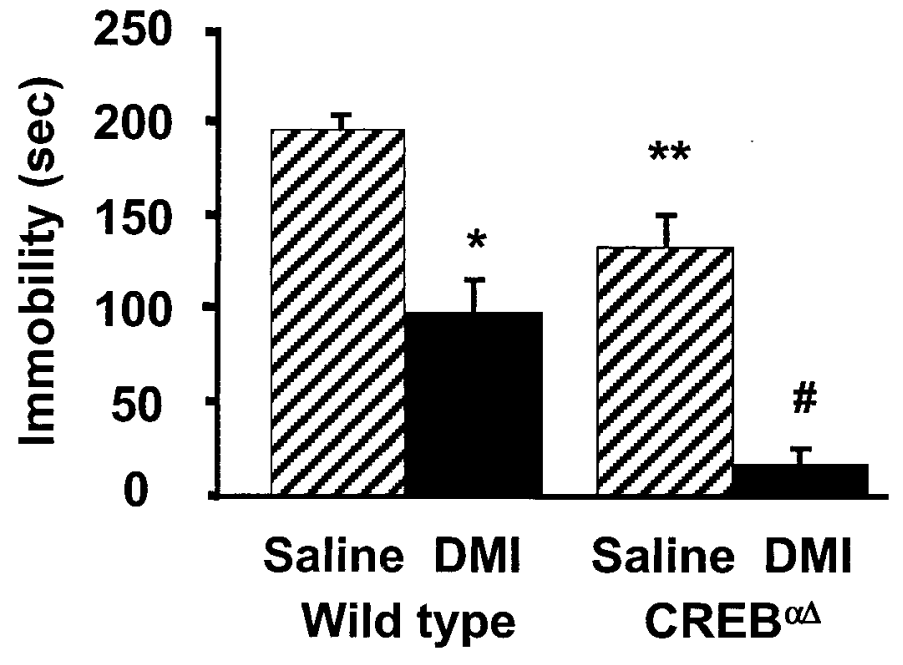

Figure 1. Behavioral response of wild-type and $\mathrm{CREB}^{\alpha \Delta}$ mice in the FST to subchronic antidepressant treatment. After a 15 min preswim on day 1, animals were administered saline or DMI ( $10.0 \mathrm{mg} / \mathrm{kg}$, i.p. $)$. On day 2 animals were administered saline or DMI $(10.0 \mathrm{mg} / \mathrm{kg}$, i.p.) $5 \mathrm{and} 1 \mathrm{hr}$ $\left(20.0 \mathrm{mg} / \mathrm{kg}\right.$, s.c.) before a $6 \mathrm{~min}$ test swim. Saline-treated CREB ${ }^{\alpha \Delta}$ mutant mice demonstrated significantly lower immobility times than saline-treated wild-type mice. Subchronic DMI treatment significantly reduced immobility times in wild-type and $\mathrm{CREB}^{\alpha \Delta}$ mutant mice compared with respective saline controls. Results are presented as mean immobility \pm SEM (in seconds). ANOVA and post hoc Fisher's pairwise comparisons revealed the following differences: ${ }^{*} p<0.05$ versus wildtype saline; $\# p<0.05$ versus mutant saline $\left(F_{(1,27)}=54.6\right) ;{ }^{* *} p<0.05$ versus wild-type saline $\left(F_{(1,27)}=24.2\right)$.

distance traveled in the Morris water maze (Graves et al., 2001). Despite the reduced baseline immobility, subchronic administration of DMI further reduced immobility times of $\mathrm{CREB}^{\alpha \Delta} \mathrm{mu}-$ tant mice and wild-type mice compared with corresponding saline control groups (Fig. 1). Desipramine dose dependently decreased immobility scores in both wild-type and $\mathrm{CREB}^{\alpha \Delta}$ mutant mice in the FST $(2.5 \mathrm{mg} / \mathrm{kg}, 5 \mathrm{mg} / \mathrm{kg}$, and $20 \mathrm{mg} / \mathrm{kg}$; data not shown).

\section{Chronic administration of the antidepressant} desipramine reduces immobility in the repeated FST

To examine the effects of chronic DMI treatment on FST immobility, animals were administered DMI daily for $14 \mathrm{~d}$ and repeatedly evaluated in the FST on days 1 and 14 (Fig. 2). CREB ${ }^{\alpha \Delta}$ mice receiving saline exhibited reduced immobility compared with saline-treated wild-type controls throughout the chronic treatment paradigm. With chronic DMI administration, both wild-type and CREB mutant mice maintained significantly reduced immobility times over the course of the study compared with respective saline controls. These data demonstrate that behavioral effects in the FST do not habituate throughout the course of a chronic drug treatment and that CREB deficiency does not alter behavioral responses to chronic DMI administration.

\section{The antidepressants desipramine and fluoxetine} reduce immobility in the TST

A second behavioral screen for antidepressant efficacy, the TST, allows for evaluation of serotonin reuptake inhibitor efficacy, which is not reliable using the FST in mice with this genetic background (Lucki et al., 2001). Similar to the results seen in the FST, saline-treated $\mathrm{CREB}^{\alpha \Delta}$ mutant mice exhibited significantly reduced immobility compared with wild-type saline controls in the TST. Immobility times of $\mathrm{CREB}^{\alpha \Delta}$ mutant mice were similar to those of wild-type mice receiving antidepressants (Fig. 3). Both

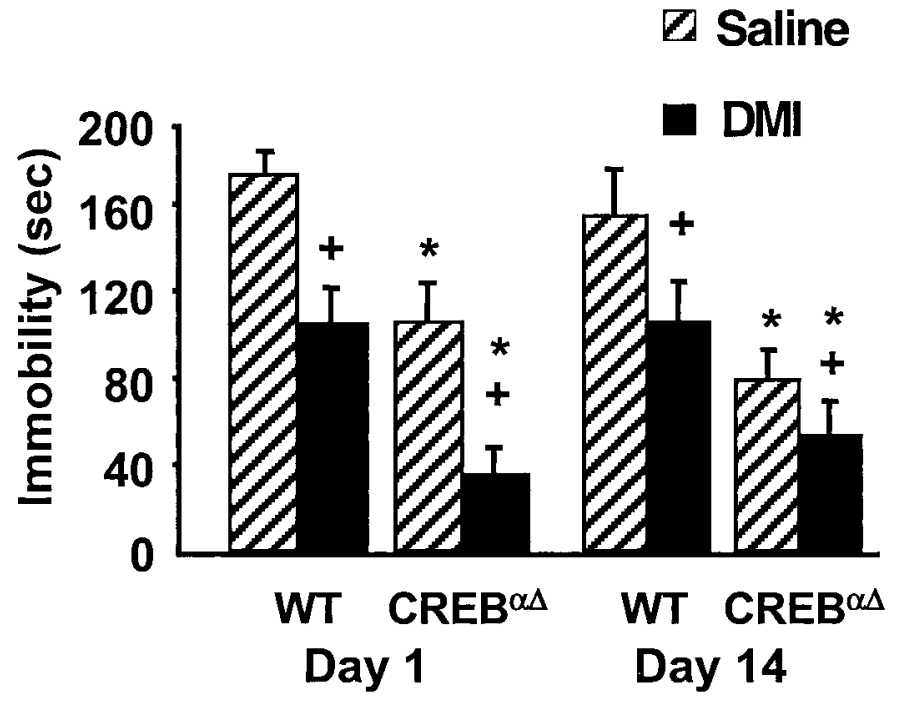

Figure 2. Behavioral response of wild-type and $\mathrm{CREB}^{\alpha \Delta}$ mice to chronic antidepressant treatment. Animals were administered DMI $(10.0 \mathrm{mg} / \mathrm{kg}$, i.p.) twice daily with $20.0 \mathrm{mg} / \mathrm{kg}$, subcutaneously administered on testing days and measured for immobility in the forced swimming test. CREB ${ }^{\alpha \Delta}$ mutant mice administered saline had significantly lower immobility times than saline-treated wild type mice. DMI administration significantly reduced immobility times in both wild-type and CREB mutant mice on days 1 and 14 of the chronic treatment paradigm. Results are presented as mean immobility \pm SEM (in seconds). ANOVA and post hoc NewmanKeuls pairwise comparisons revealed the following differences: $+p<0.05$ versus saline, corresponding gene and day; ${ }^{*} p<0.05$ versus different gene, same treatment and day.

DMI and FLX significantly reduced immobility times in wildtype mice compared with wild-type saline controls and in the $\mathrm{CREB}^{\alpha \Delta}$ mutant mice compared with mutant saline controls. Together these data demonstrate that both FLX and DMI exert characteristic behavioral effects in mice despite a deficiency in CREB protein.

\section{Subchronic desipramine treatment suppresses corticosterone response to acute swim stress exposure}

The FST is a potent activator of the HPA axis, therefore, to examine the stress-induced endocrine response in CREBdeficient animals, mice were killed 20 min after FST exposure, and blood samples were taken for corticosterone analysis. Wildtype and mutant mice exhibited similar significant elevations in corticosterone after forced swim stress compared with respective non-swim stress controls (Fig. 4). DMI administered in three doses $(10 \mathrm{mg} / \mathrm{kg}$, i.p.; $10 \mathrm{mg} / \mathrm{kg}$, i.p.; and $20 \mathrm{mg} / \mathrm{kg}$, s.c.) over 24 $\mathrm{hr}$ significantly attenuated swim stress-induced elevations in plasma corticosterone in wild-type and $\mathrm{CREB}^{\alpha \Delta}$ mutant mice compared with saline-treated stress controls. These data demonstrate that swim stress-induced HPA activation is not impaired in CREB-deficient mice and that the ability of DMI to exert effects on the acute endocrine response to swim stress is maintained in the absence of intact CREB function.

\section{CREB deficiency prevents BDNF mRNA upregulation after chronic desipramine treatment}

The ability of chronic and subchronic administration of DMI and FLX to alter BDNF transcription was examined in CREB mutant mice. Subchronic administration of DMI or FLX had no effect on transcriptional regulation of BDNF mRNA in wild-type or 


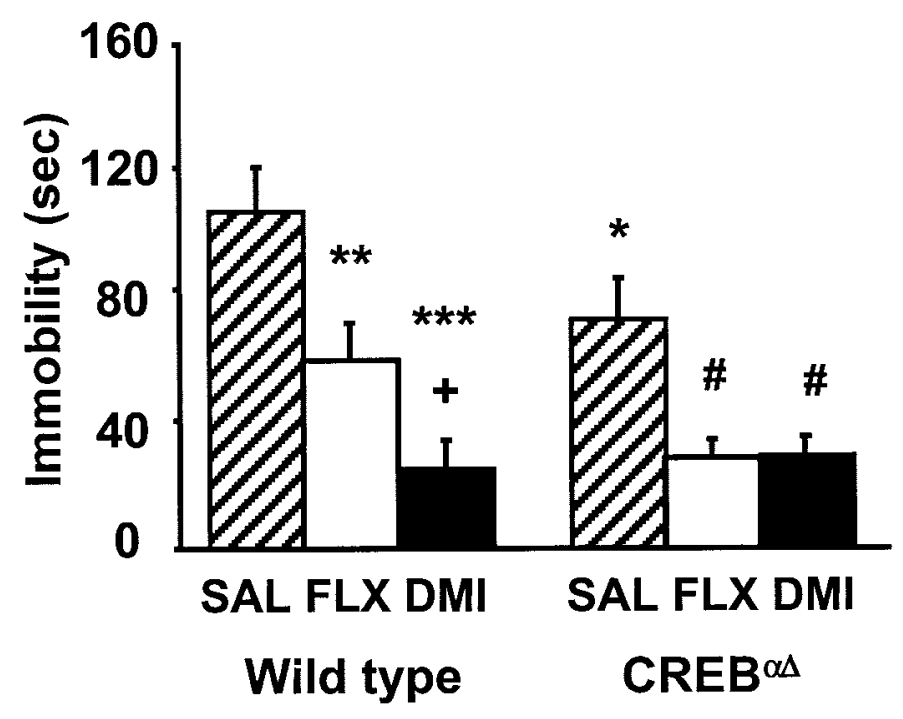

Figure 3. Behavioral response of wild-type and $\mathrm{CREB}^{\alpha \Delta}$ mice in the TST to subchronic antidepressant treatment. Animals were administered saline, DMI, or FLX (20 mg/kg, i.p.) $30 \mathrm{~min}$ before a 6 min test session. Saline-treated $\mathrm{CREB}^{\alpha \Delta}$ mutant mice demonstrated significantly lower immobility times than saline-treated wild-type mice. Subchronic FLX and DMI significantly reduced immobility times in both wild-type and $\mathrm{CREB}^{\alpha \Delta}$ mutant mice compared with respective saline controls. Results are presented as mean immobility \pm SEM (in seconds). ANOVA and post hoc Fisher's pairwise comparisons revealed the following differences: ${ }^{* *} p<0.05$ versus wild-type saline; $* * * p<0.05$ versus wild-type saline; $+p<0.05$ versus wild-type fluoxetine; $\# p<0.05$ versus mutant saline $\left(F_{(2,48)}=16.3\right) ;{ }^{*} p<0.05$ versus wild-type saline $\left(F_{(1,48)}=3.8\right)$.

$\mathrm{CREB}^{\alpha \Delta}$ mutant mice (data not shown). These data demonstrate that BDNF mRNA upregulation is not required for behavioral antidepressant efficacy (Fig. 1).

After chronic DMI administration, wild-type mice exhibited significantly elevated BDNF mRNA levels in the frontal cortex (Fig. $5 A$ ). In contrast, no significant increase was seen in $\mathrm{CREB}^{\alpha \Delta}$ mutant mice. Similarly, in the hippocampus of wild-type mice DMI significantly elevated BDNF mRNA levels compared with saline-treated controls (Fig. 5B), which is in agreement with previous studies (Nibuya et al., 1995). However, again in $\mathrm{CREB}^{\alpha \Delta}$ mutant mice BDNF mRNA levels were unchanged compared with saline controls. Conversely, chronic FLX did not alter BDNF mRNA expression in either region of wild-type or $\mathrm{CREB}^{\alpha \Delta}$ mutant mice, suggesting that BDNF is not a final common target of antidepressant action in this model. These data clearly demonstrate that $\mathrm{CREB}$ is an upstream activator of BDNF and is critical for DMI-induced elevations of BDNF mRNA after chronic antidepressant administration.

\section{DISCUSSION}

Recent studies have suggested a role for CREB in mediating the actions of antidepressant drugs. In the current studies, the $\mathrm{CREB}^{\alpha \Delta}$ mutant mouse model is a useful tool for examining the relationship between CREB activation and adaptational responses to antidepressant drugs. This mouse model has previously been described as a partial loss of function mutation in which the $\alpha$ and $\Delta$ isoforms of CREB are absent, whereas a minor splice variant of CREB, CREB $\beta$, is upregulated (Blendy et al., 1996). Despite this, functional CRE-binding activity is reduced by $\sim 90 \%$ in the brains of these mice (Walters and Blendy, 2001). Although CREB $\beta$ is not efficient in forming DNA binding complexes in the brains of $\mathrm{CREB}^{\alpha \Delta}$ mutant mice (Pandey et al.,

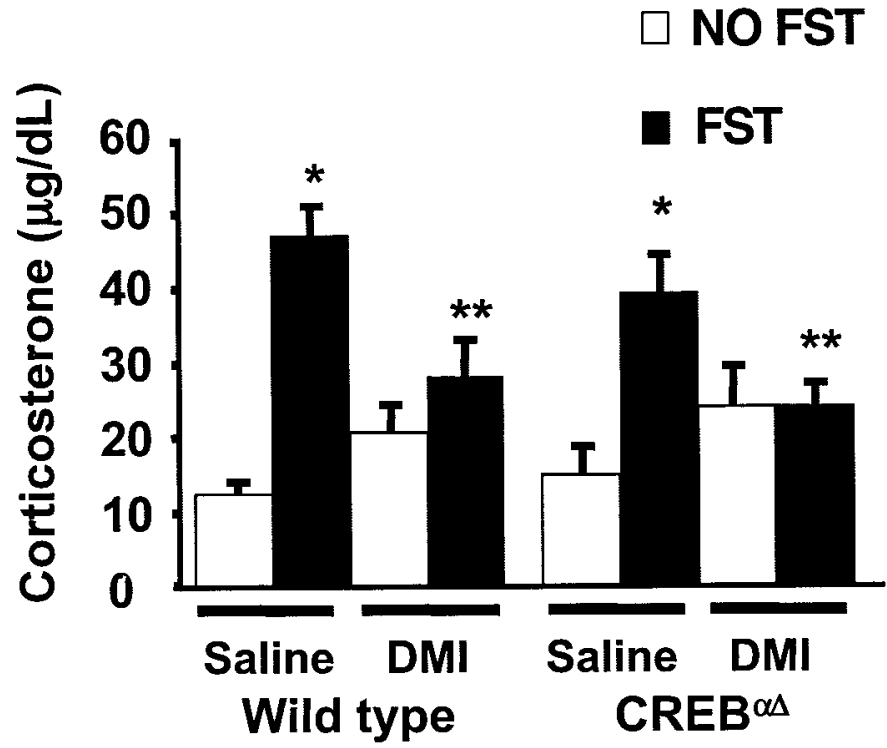

Figure 4. Regulation of corticosterone after exposure to the forced swimming test. Animals were examined for changes in the stress hormone corticosterone with and without acute exposure to the FST. In wild-type and $\mathrm{CREB}^{\alpha \Delta}$ mutant mice, swim stress induced a significant elevation in corticosterone compared with non-swim stressed control mice. Subchronic administration of DMI significantly blunted the elevation in corticosterone in both wild-type and mutant mice compared with respective saline controls. Values are plotted as mean corticosterone \pm SEM (in micrograms per decaliter). ANOVA and post hoc Student-NewmanKeuls pairwise comparisons revealed the following differences: ${ }^{*} p=0.05$ versus corresponding non-swim stressed saline group $\left(F_{(1,50)}=31\right)$ and $* * p<0.05$ versus corresponding swim-stressed saline group $\left(F_{(1,50)}=2\right)$.

2000), this isoform must have some function in vivo, most likely in peripheral tissues, because mice lacking all three CREB isoforms $(\alpha, \beta$, and $\Delta)$ are not viable (Rudolph et al., 1998). Thus, the $\mathrm{CREB}^{\alpha \Delta}$ mutant mice represent a useful animal model for studying the role of CREB in vivo.

Our results using this model are the first to demonstrate clearly that CREB acts upstream of BDNF and therefore, is essential for transcriptional alterations in BDNF mRNA after chronic antidepressant treatment. These data are consistent with recent findings that chronic exposure to antidepressants produce long-term adaptations in cellular signaling mechanisms in rats (Nibuya et al., 1995, 1996; Thome et al., 2000). Finally, the present data also demonstrate that both the behavioral and endocrine effects of antidepressant drugs tested may occur via alternate mechanisms that are not CREB-dependent.

The behavioral efficacy of antidepressant drugs is widely assessed using two common models of stress-induced behavioral depression, the FST and the TST. In both paradigms the animal is subjected to an inescapable stress and typically responds with alternating bouts of escape-oriented behavior and immobility. All major classes of antidepressants effectively reduce immobility in both tests, confirming their validity as drug-screening paradigms (Borsini and Meli, 1988; Porsolt, 2000; Lucki, 2001). Of interest, $\mathrm{CREB}^{\alpha \Delta}$ mutant mice show significantly less immobility in their baseline response in both the FST and the TST. This is not caused by general alterations in activity because these mice do not demonstrate changes in home cage motor activity or swimming behavior (Graves et al., 2001; Walters and Blendy, 2001). Similar results have been reported in the rat in which reductions in CREB function are achieved by intracranial injection of a transdominant 
A
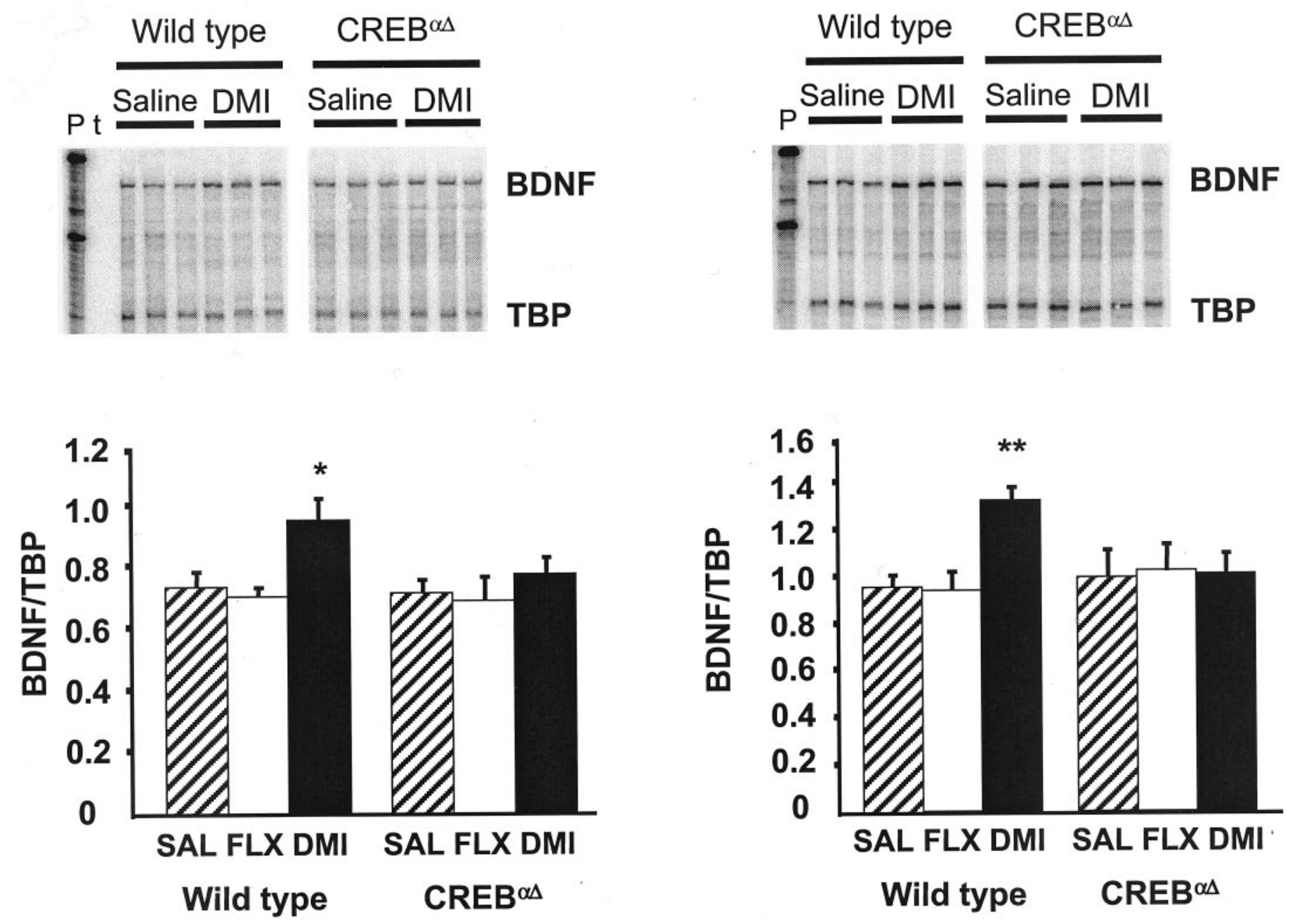

Figure 5. RNase protection analysis of BDNF gene expression after chronic antidepressant treatment. The steady-state levels of BDNF and TBP (as internal standard) mRNAs were determined by RNase protection assay after chronic (21 d) drug administration in the frontal cortex and hippocampus of wild-type and $\mathrm{CREB}^{\alpha \Delta}$ mutant mice. Twenty micrograms of total RNAs were cohybridized with both riboprobes and analyzed as described in Materials and Methods. Three representative lanes are shown for saline and DMI treatment groups from wild-type and CREB ${ }^{\alpha \Delta}$ mutant mice $(A, B$, top). Radioactive bands for BDNF were quantified using a phosphorimager, and signals were normalized to those of TBP and plotted ( $A$, $B$, bottom). DMI administration increased BDNF mRNA in the frontal cortex $(A)$ and hippocampus $(B)$ of wild-type mice compared with saline controls. $P$, Free probes; $t$, tRNA as control. ANOVA and post hoc Fisher's pairwise comparisons revealed the following differences: ${ }^{*} p<0.05$ versus wild-type saline $\left(F_{(2,43)}=3.1\right) ;{ }^{* *} p<0.05$ versus wild-type saline $\left(F_{(2,54)}=3.6\right)$. In CREB ${ }^{\alpha \Delta}$ mutant mice, however, DMI administration did not alter BDNF mRNA in the frontal cortex or hippocampus $(A, B$, respectively). No increases in BDNF mRNA were observed in either the frontal cortex or hippocampal regions after chronic FLX in wild-type or $\mathrm{CREB}^{\alpha \Delta}$ mutant mice $(A, B$, respectively).

negative form of CREB into the nucleus accumbens. These transgenic animals demonstrate an increase in latency to immobility in the FST, a behavior associated with antidepressant drug action (Pliakas et al., 2001). Together, these data suggest that CREB reduction results in similar behavioral responses as those associated with antidepressant drug effects. In contrast, studies in the rat have shown that overexpression of CREB via herpes simplex virus-mediated gene transfer in the dentate gyrus produces antidepressant-like behaviors in the FST and learned helplessness paradigms (Chen et al., 2001). It should be noted, however, that in these experiments, overexpression of CREB in the CA1 or CA3 regions of the hippocampus or the frontal cortex did not produce antidepressant behaviors. The apparent discrepancy in results suggest that modulation of behavioral antidepressant ef- fects by CREB must depend on relative levels of the protein as well as its discrete localization in brain regions.

Despite the altered baseline mobility score, the tricyclic antidepressant desipramine reduced immobility in the FST in both $\mathrm{CREB}^{\alpha \Delta}$ mutant and wild-type mice. This further supports the notion that baseline immobility scores in these tests can be dissociated from the behavioral effects of antidepressants. Lesion and genetic studies have been used to block the norepinephrine and serotonin reuptake inhibitors without affecting baseline immobility scores, demonstrating that the underlying neurochemical substrates for immobility behavior are different from those sensitive to the effects of antidepressants (Page et al., 1999; Cryan et al., 2001a,b). The ability of desipramine to exert effects on behavioral immobility in the FST was observed not only after sub- 
chronic administration, but also repeatedly, over the course of chronic desipramine treatment for $14 \mathrm{~d}$. These findings demonstrate that neurochemical mechanisms that mediate behavioral effects of DMI in the FST remain functional despite CREB reduction. Furthermore, these data are the first to report that immobility scores remain consistent over repeated trials in the FST. Although these mice have been shown to have deficits in certain types of learning and memory tasks (Bourtchuladze et al., 1994), there does not appear to be a strong learning effect associated with the FST beyond the initial test session.

The selective serotonin reuptake inhibitor fluoxetine also reduces immobility in the mouse FST, but its effectiveness in our paradigm is compromised by the genetic background that harbors the CREB mutation (129SvEv:C57Bl/6) (Lucki et al., 2001). Therefore, a second paradigm, the TST, was used to measure behavioral effects of antidepressant treatment because it is sensitive to DMI and FLX in the background strain of the $\mathrm{CREB}^{\alpha \Delta}$ mutant mice. Similar to the FST, baseline immobility is reduced in the TST in the CREB ${ }^{\alpha \Delta}$ mutant mice compared with wild-type mice. The ability of both DMI and FLX to further reduce immobility in CREB-deficient mice compared with saline controls is maintained. It is of interest that DMI appeared significantly more effective than FLX in the TST in wild-type mice, whereas these drugs appeared to be equally effective in the CREB mutant mice. The lack of differential response in the $\mathrm{CREB}^{\alpha \Delta}$ mutant mice may be attributable to the reduced baseline immobility in these mice, resulting in a "floor effect" after drug administration.

Although the mechanisms underlying antidepressant behaviors in the FST and TST are still unclear, recent data has suggested that behavioral effects may be mediated strongly by genetic factors (Vaugeois et al., 1996; Lopez-Rubalcava and Lucki, 2000; Lucki et al., 2001). One interpretation of the behavioral immobility observed in the FST and TST is that immobility behavior allows for adaptive retraction from the inescapable stress of forced swimming or tail suspension, which is interrupted with bouts of escape-motivated activity. Together these alternating behavioral responses comprise a coping strategy (Thierry et al., 1984) in which immobility behaviors represent the psychological concept of "entrapment" described in clinical depression (Dixon, 1998; Gilbert and Allan, 1998; Lucki et al., 2001). Therefore, a genetic basis for behavioral immobility in the FST and TST may involve alterations in the development of stress-induced behavioral depression. It is therefore important to consider the effects of stress on HPA axis activation.

Stress resulting from FST exposure activates the HPA axis, causing significant elevations of corticosterone in wild-type and $\mathrm{CREB}^{\alpha \Delta}$ mutant mice. The elevations are attenuated by subchronic administration of DMI in both groups. These data are in agreement with previous rat studies that document the attenuation of stress-associated elevations in serum corticosterone by DMI but not by other antidepressant agents (Connor et al., 1997). DMI treatment is suggested to reduce serum corticosterone concentrations by a variety of mechanisms, including suppression of corticotropin releasing factor (CRF) expression (Brady et al., 1991; Centeno and Volosin, 1997). There is increasing evidence that CREB may activate CRF transcription (Spengler et al., 1992; Guardiola-Diaz et al., 1994), therefore, dramatically reduced corticosterone response may have been expected in CREB-deficient mice. In contrast, the present data do not show any alterations in either basal or stress induced corticosterone release in the $\mathrm{CREB}^{\alpha \Delta}$ mutant mice compared with wild-type controls. Fur- thermore, DMI-induced suppression of serum corticosterone is the same in wild-type and $\mathrm{CREB}^{\alpha \Delta}$ mutant mice. Therefore, while DMI may dampen HPA activation by reducing CRF release, this effect is occurring in the absence of intact CREB function.

Although CREB does not appear to be mediating the behavioral or acute endocrine effects of antidepressant agents, recent evidence supports the idea that CREB is part of a molecular pathway activated after chronic antidepressant treatment. Increases in total CREB mRNA are observed in the hippocampus and dentate gyrus after chronic antidepressant treatment in rats (Nibuya et al., 1996). In addition, human postmortem studies reveal increased levels of total CREB immunoreactivity in antidepressant-treated major depressive disorder (MDD) patients compared with control patients and reduced CREB immunoreactivity in untreated MDD patients (Dowlatshahi et al., 1998).

Because CREB is a potent transcriptional activator, alterations in CREB levels and/or activity can influence target gene regulation, which in turn can contribute to the overall efficacy of antidepressants. One such gene target is BDNF, which can be activated by CREB via CRE elements located in its promoter region (Shieh et al., 1998; Tao et al., 1998). Changes in BDNF mRNA expression have been correlated with antidepressant treatment. Acute and chronic electroconvulsive seizure treatment increased BDNF and its receptor, trkB mRNA in the rat frontal cortex and hippocampus (Nibuya et al., 1995). Similarly, chronic antidepressant treatment increased BDNF and trkB mRNA in the hippocampus (Nibuya et al., 1995). BDNF inf usion into raphe nuclei or midbrain regions produced antidepressant-like behaviors in two rodent models of depression (Siuciak et al., 1997). In addition, BDNF may exert antidepressant actions by promoting neurogenesis and neuronal survival (Ghosh et al., 1994; Lindvall et al., 1994; Malberg et al., 2000). In the present study, chronic, but not subchronic DMI treatment upregulated BDNF mRNA in the frontal cortex and hippocampus of wild-type mice. This effect was blocked in $\mathrm{CREB}^{\alpha \Delta}$ mutant mice in both regions. These findings clearly establish that CREB acts upstream of BDNF in the molecular pathway that is activated after chronic antidepressant administration. Fluoxetine was unable to induce BDNF mRNA upregulation in wild-type or mutant mice in this model. Although previous studies have demonstrated increased BDNF mRNA in the hippocampus, but not the frontal cortex after FLX treatment, these discrepancies may be attributable to the method and/or sensitivity of mRNA analyses used (in situ hybridization vs RNase protection assay) as well as species differences (rat vs mouse).

Treatment for depression involves relief of behavioral signs and symptoms of the disease, as well as a maintained therapeutic efficacy, which appears to be necessary for prevention of recurrent episodes (Goodwin and Jamison, 1990). The present findings demonstrate that CREB may be one critical mediator of the transcriptional effects of antidepressants, however, the mechanisms that underlie the behavioral and endocrine effects of subchronic antidepressant administration appear to be less dependent on CREB activation. Further studies will be required to correlate the various endpoints of antidepressant action described here, with the short-term behavioral and long-term maintenance phases of clinical efficacy. Complex neuropsychiatric diseases, such as depression, can arise from multiple genetic factors. Thus, it is likely that the treatment of such a disease would need to impact on several molecular pathways. One possibility raised by 
these results is that activation of CREB may not be necessary for effects that mediate symptom reduction. In contrast, CREB activation, along with target gene expression and alterations of neuronal pathways may underlie the ability of chronic antidepressant treatment to prevent recurrent depressive episodes.

\section{REFERENCES}

Baez M, Volosin M (1994) Corticosterone influences forced swiminduced immobility. Pharmacol Biochem Behav 49:729-736.

Blendy JA, Kaestner KH, Schmid W, Gass P, Schutz G (1996) Targeting of the CREB gene leads to up-regulation of a novel CREB mRNA isoform. EMBO J 15:1098-1106.

Borsini F, Meli A (1988) Is the forced swimming test a suitable model for revealing antidepressant activity. Psychopharmacology 92:147-160.

Bourtchuladze R, Frenguelli B, Blendy J, Cioffi D, Schutz G, Silva AJ (1994) Deficient long-term memory in mice with a targeted mutation of the cAMP-responsive element-binding protein. Cell 79:59-68.

Brady LS, Whitfield Jr HJ, Fox RJ, Gold PW, Herkenham M (1991) Longterm antidepressant administration alters corticotropin-releasing hormone, tyrosine hydroxylase, and mineralocorticoid receptor gene expression in rat brain. Therapeutic implications. J Clin Invest 87:831-837.

Centeno VA, Volosin M (1997) Chronic treatment with desipramine: effect on endocrine and behavioral responses induced by inescapable stress. Physiol Behav 62:939-944.

Chen AC, Shirayama Y, Shin K, Neve RL, Duman RS (2001) Expression of the cAMP response element binding protein (CREB) in hippocampus produces an antidepressant effect. Biol Psychiatry 49:753-762.

Chomczynski P, Sacchi N (1987) Single-step method of RNA isolation by acid guanidinium thiocyanate-phenol-chloroform extraction. Anal Biochem 162:156-159.

Connor TJ, Kelly JP, Leonard BE (1997) Forced swim test-induced neurochemical endocrine, and immune changes in the rat. Pharmacol Biochem Behav 58:961-967.

Cryan JF, Dalvi A, Jin SH, Hirsch BR, Lucki I, Thomas SA (2001a) Use of dopamine-beta-hydroxylase-deficient mice to determine the role of norepinephrine in the mechanism of action of antidepressant drugs. J Pharmacol Exp Ther 298:651-657.

Cryan JF, Page ME, Lucki I (2001b) Noradrenergic lesions differentially alter the antidepressant-like effects of reboxetine. Eur J Pharmacol 436:197-205.

Dixon AK (1998) Ethological strategies for defense in animals and humans: their role in some psychiatric disorders. Br J Med Psychol 71:417-445.

Dowlatshahi D, MacQueen GM, Wang JF, Young LT (1998) Increased temporal cortex CREB concentrations and antidepressant treatment in major depression. Lancet 352:1754-1755.

Duman RS, Heninger GR, Nestler EJ (1997) A molecular and cellular theory of depression. Arch Gen Psychiatry 54:597-606.

Ghosh A, Carnahan J, Greenberg ME (1994) Requirement for BDNF in activity-dependent survival of cortical neurons. Science 263:1618-1623.

Gilbert P, Allan S (1998) The role of defeat and entrapment (arrested flight) in depression: an exploration of an evolutionary view. Psychol Med 28:585-598.

Goodwin FK, Jamison KR (1990) Manic-depressive illness. New York: Oxford UP.

Graves L, Dalvi A, Lucki I, Blendy JA, Abel T (2001) Behavioral analysis of the CREB $\alpha \Delta$ mutation on a B6/129 F1 hybrid background. Hippocampus, in press.

Guardiola-Diaz HM, Boswell C, Seasholtz AF (1994) The cAMPresponsive element in the corticotropin-releasing hormone gene mediates transcriptional regulation by depolarization. J Biol Chem 269:14784-14791.

Heninger GR, Charney DS (1987) Mechanisms of action of antidepressant treatment: Implications for the etiology and treatment of depressive disorders. In: Psychopharmacology: the third generation of progress (Meltzer HY, ed), pp 535-544. New York: Raven.

Hummler E, Cole TJ, Blendy JA, Ganss R, Aguzzi A, Schmid W, Beermann F, Schutz G (1994) Targeted mutation of the CREB gene: compensation within the CREB/ATF family of transcription factors. Proc Natl Acad Sci USA 91:5647-5651.

Jacobson L, Sapolsky R (1991) The role of the hippocampus in feedback regulation of the hypothalamic- pituitary-adrenocortical axis. Endocr Rev 12:118-134.

Kaestner KH, Ntambi JM, Kelly Jr TJ, Lane MD (1989) Differentiationinduced gene expression in 3T3-L1 preadipocytes. A second differentially expressed gene encoding stearoyl-CoA desaturase. J Biol Chem 264:14755-14761.

Lindvall O, Kokaia Z, Bengzon J, Elmer E, Kokaia M (1994) Neurotrophins and brain insults. Trends Neurosci 17:490-496.
Lopez-Rubalcava C, Lucki I (2000) Strain differences in the behavioral effects of antidepressant drugs in the rat forced swimming test. Neuropsychopharmacology 22:191-199.

Lucki I (2001) A prescription to resist proscriptions for murine models of depression. Psychopharmacology (Berl) 153:395-398.

Lucki I, Dalvi A, Mayorga AJ (2001) Sensitivity to the effects of pharmacologically selective antidepressants in different strains of mice. Psychopharmacology (Berl) 155:315-322.

Malberg JE, Eisch AJ, Nestler EJ, Duman RS (2000) Chronic antidepressant treatment increases neurogenesis in adult rat hippocampus. J Neurosci 20:9104-9110.

Mayorga AJ, Lucki I (2001) Limitations on the use of the C57BL/6 mouse in the tail suspension test. Psychopharmacology (Berl) 155:110-112.

Nibuya M, Morinobu S, Duman RS (1995) Regulation of BDNF and trkB mRNA in rat brain by chronic electroconvulsive seizure and antidepressant drug treatments. J Neurosci 15:7539-7547.

Nibuya M, Nestler EJ, Duman RS (1996) Chronic antidepressant administration increases the expression of cAMP response element binding protein (CREB) in rat hippocampus. J Neurosci 16:2365-2372.

Page M, Detke MJ, Dalvi A, Kirby L, Lucki I (1999) Serotonergic mediation of the effects of fluoxetine, but not desipramine, in the rat forced swimming test. Psychopharmacology 147:162-167.

Pandey SC, Mittal N, Silva AJ (2000) Blockade of cyclic AMPresponsive element binding in the brain of CREB delta/alpha mutant mice. NeuroReport 2:2577-2580.

Pliakas AM, Carlson RR, Neve RL, Konradi C, Nestler EJ, Carlezon Jr WA (2001) Altered responsiveness to cocaine and increased immobility in the forced swim test associated with elevated cAMP response element-binding protein expression in nucleus accumbens. J Neurosci 21:7397-7403.

Porsolt RD (2000) Animal models of depression: utility for transgenic research. Rev Neurosci 11:53-58.

Porsolt RD, Bertin A, Jalfre M (1977) Behavioral despair in mice: a primary screening test for antidepressants. Arch Int Pharmacodyn Ther 229:327-336.

Rudolph D, Tafuri A, Gass P, Hammerling GJ, Arnold B, Schutz G (1998) Impaired fetal $\mathrm{T}$ cell development and perinatal lethality in mice lacking the cAMP response element binding protein. Proc Natl Acad Sci USA 95:4481-4486.

Shieh PB, Hu SC, Bobb K, Timmusk T, Ghosh A (1998) Identification of a signaling pathway involved in calcium regulation of BDNF expression. Neuron 20:727-740.

Silva AJ, Simpson EM, Takahashi JS, Lipp H-P, Nakanishi S, Wehner JM, Giese KP, Tully T, Abel T, Chapman PF, Fox K, Grant S, Itohara S, Lathe R, Mayford M, McNamara JO, Morris RJ, Picciotto M, Roder J, Shin H-S, et al. (1997) Mutant mice and neuroscience: Recommendations concerning genetic background. Neuron 19:755-759.

Siuciak JA, Lewis DR, Wiegand SJ, Lindsay RM (1997) Antidepressantlike effect of brain-derived neurotrophic factor (BDNF). Pharmacol Biochem Behav 56:131-137.

Spengler D, Rupprecht R, Van LP, Holsboer F (1992) Identification and characterization of a $3^{\prime}, 5^{\prime}$-cyclic adenosine monophosphate-responsive element in the human corticotropin-releasing hormone gene promoter. Mol Endocrinol 6:1931-1941.

Steru L, Chermat R, Thierry B, Simon P (1985) The tail suspension test: a new method for screening antidepressants in mice. Psychopharmacology 85:367-370.

Sunal R, Gumusel B, Kayaalp SO (1994) Effect of changes in swimming area on results of "behavioral despair test." Pharmacol Biochem Behav 49:891-896.

Tamura T, Sumita K, Fujino I, Aoyama A, Horikoshi M, Hoffmann A, Roeder RG, Muramatsu M, Mikoshiba K (1991) Striking homology of the "variable" N-terminal as well as the "conserved core" domains of the mouse and human TATA-factors (TFIID). Nucleic Acids Res 19:3861-3865.

Tao X, Finkbeiner S, Arnold DB, Shaywitz AJ, Greenberg ME (1998) $\mathrm{Ca}^{2+}$ influx regulates BDNF transcription by a CREB family transcription factor-dependent mechanism. Neuron 20:709-726.

Thierry B, Steru L, Chermat R, Simon P (1984) Searching-waiting strategy: a candidate for an evolutionary model of depression? Behav Neural Biol 41:180-189.

Thome J, Sakai N, Shin K, Steffen C, Zhang YJ, Impey S, Storm D, Duman RS (2000) cAMP response element-mediated gene transcription is upregulated by chronic antidepressant treatment $\mathrm{J}$ Neurosci 20:4030-4036.

Vaugeois JM, Odievre C, Loisel L, Costentin J (1996) A genetic mouse model of helplessness sensitive to imipramine. Eur J Pharmacol 316:R1-R2.

Walters CL, Blendy JA (2001) Different requirements for cAMP response element binding protein in positive and negative reinforcing properties of drugs of abuse. J Neurosci 21:9438-9444. 